\title{
Exigências de lisina digestível para codornas japonesas na fase de postura
}

\section{Fernando Guilherme Perazzo Costa $^{1}$, Valéria Pereira Rodrigues ${ }^{2}$, Cláudia de Castro Goulart ${ }^{3,4}$, Raul da Cunha Lima Neto ${ }^{3}$, Janete Gouveia de Souza ${ }^{3}$, José Humberto Vilar da Silva ${ }^{5}$}

\footnotetext{
${ }^{1}$ Departamento de Zootecnia da UFPB - Areia/PB.

2 Curso de Graduação em Zootecnia da UFPB - Areia/PB.

3 Programa de Doutorado Integrado em Zootecnia da UFPB - Areia/PB.

${ }^{4}$ Curso de Zootecnia da UVA - Sobral/CE, Bolsista da Funcap.

${ }^{5}$ Departamento de Agropecuária/CFT/UFPB - Bananeiras /PB.
}

RESUMO - Objetivou-se estimar as exigências nutricionais de lisina digestível para codornas japonesas em postura. Foram utilizadas 240 codornas distribuídas em delineamento de blocos casualizados, com cinco tratamentos, cada um com seis repetições de oito aves. Os tratamentos consistiram de uma ração basal deficiente em lisina e suplementada com L-lisina.HCL, de modo a apresentar 0,$88 ; 0,96 ; 1,04 ; 1,12$ ou 1,20\% de lisina digestível. Avaliaram-se o consumo de ração (CR), a produção de ovos (PR), o peso (PO) e a massa (MO) do ovo, a conversão alimentar por massa (CMO) e por dúzia (CDZ) de ovos, os pesos de albúmen (PA), gema (PG) e casca (PC), as porcentagens de albúmen (\%A), gema (\%G) e casca (\%C) e a gravidade específica (GE) dos ovos. O nível de lisina digestível da ração influenciou o consumo de ração, enquanto a produção de ovos respondeu de forma quadrática aos níveis de lisina. As demais variáveis analisadas não foram influenciadas pelo nível de lisina digestível da ração. A exigência de lisina digestível para codornas japonesas em postura foi estimada em 1,03\% da ração, que corresponde a um consumo diário de $292 \mathrm{mg}$ de lisina digestível.

Palavras-chave: aminoácido, Coturnix coturnix japonica, produção de ovos

\section{Digestible lysine requirements for laying Japanese quails}

\begin{abstract}
The objective was to estimate the nutritional requirements of digestible lysine for Japanese laying quails. Two hundred and forty Japanese quails were allotted to a completely randomized block designs, with five diets, with six replications of eight birds each. Diets consisted of a basal ration deficient in lysine and supplemented with five levels 0.88 , 0.96, $1.04,1.12$ or $1.20 \%$ ) of digestible lysine. Feed consumption, egg production, egg weight and egg mass, feed conversion by egg mass (FCEM) and by dozen egg were evaluated. It was also evaluated, albumen weight, yolk weight and shell weight, percentages of albumen, yolk and shell and egg specific gravity. Dietary digestible lysine level linearly influenced feed intake, while egg production was affected in a quadratic faction by digestible lysine levels. The other characteristics were not affected by dietary digestible lysine levels. Dietary digestible lysine requirement for Japanese laying quails was estimated in $1.03 \%$, which correspond to a daily intake of $292 \mathrm{mg}$ of digestible lysine.
\end{abstract}

Key Words: amino acid, Coturnix coturnix japonica, egg production

\section{Introdução}

A expansão da coturnicultura no Brasil tem merecido destaque, pois inicia nova fase no País, superando o amadorismo e consolidando-se como exploração comercial (Leandro et al., 2005). A produção torna-se ainda maior pelo fato de as codornas apresentarem precocidade na maturidade sexual, crescimento rápido e elevada produção de ovos, o que tem motivado pesquisadores à busca por melhorias no desempenho e à avaliação das exigências nutricionais dessas aves, uma vez que é comum a utilização de rações para poedeiras comerciais na alimentação de codornas.

O maior impacto financeiro na produção é a alimentação. Há, no entanto, pouca informação sobre a nutrição de codornas nas fases inicial, de crescimento e de produção (postura). As tabelas de exigências nutricionais disponíveis não apresentam uniformidade nos períodos determinados para as diversas fases de desenvolvimento nem nos níveis nutricionais recomendados. Atualmente, as formulações de rações para codornas são feitas com base em resultados da literatura internacional, como os preditos 
pelo NRC (1994), pouco condizentes com as condições brasileiras (Ton, 2007).

As proteínas e os aminoácidos são essenciais na formulação de dietas para aves, pois asseguram a produção e o bem-estar das aves e, conforme sua utilização nas dietas, possibilitam reduzir a poluição ambiental (Silva et al., 2005). De acordo com Ton (2007), durante muitos anos, a formulação de rações para aves foi baseada no conceito de proteína bruta (PB), que resulta em dietas com conteúdo de aminoácidos superior à exigência dos animais. A digestão e o metabolismo desses aminoácidos consumidos em excesso aumentam o gasto calórico corporal provocando a excreção de volume excessivo de ácido úrico, além de maior gasto de energia. O excesso de aminoácidos circulante no sangue pode provocar ainda a diminuição do consumo de ração pelos animais (Goulart, 1997).

A lisina é o segundo aminoácido limitante em rações para aves e o interesse por estudos com esse aminoácido na alimentação de aves se justifica principalmente pelo fato de que a lisina tem baixo custo de suplementação e pode afetar o desempenho das codornas. Uma de suas funções mais importantes é a participação na deposição de proteína corporal e na síntese de carnitina, que atua no transporte de ácidos graxos para a $\alpha$-oxidação na mitocôndria. O excesso de lisina pode ocasionar prejuízos metabólicos como o antagonismo com outros aminoácidos, como a arginina, uma vez que disputam o mesmo sítio de absorção. Considerado aminoácido padrão no conceito de proteína ideal, a lisina tem sido utilizada como referência para estimativa das exigências dos demais aminoácidos (Barreto et al., 2006), pois, alterando seus níveis na dieta, concomitantemente, modificam-se os níveis dos outros aminoácidos (Pinto et al., 2003).

Oliveira et al. (1999) utilizaram rações com 14,10\% PB e recomendaram níveis de 1,07 e 1,08\% de lisina total para maior porcentagem de postura e melhor peso médio dos ovos das codornas, respectivamente, e 1,0\% de lisina para rações com 19,0\% de PB. Ribeiro et al. (2003), no entanto, indicaram 1,07 e 1,15\% de lisina digestível para dietas com 20 e $23 \%$ de proteína bruta, respectivamente, e Pinto et al. (2003) sugeriram 1,117\% de lisina digestível para dietas com 19,56\% proteína bruta para codornas japonesas em postura.

Portanto, objetivou-se determinar as exigências de lisina digestível para codornas japonesas em postura.

\section{Material e Métodos}

O experimento foi conduzido no Módulo de Avicultura do Departamento de Zootecnia do Centro de Ciências Agrárias da Universidade Federal da Paraíba, Campus II, no município de Areia, Paraíba. Foram utilizadas 240 codornas japonesas em postura com peso inicial de 169,1 \pm 0,8 g, no período de 94 a 178 dias de idade, distribuídas em delineamento de blocos casualizados, com cinco tratamentos e seis repetições de oito aves.

Nos 20 dias que antecederam o experimento, a produção de ovos foi anotada e a taxa de postura no período foi calculada para uniformização das parcelas. As aves foram separadas por categoria e intervalos de produção (porcentagem de postura), cuja variação inicial da taxa de postura foi de 64 a $87 \%$. Iniciou-se, então, a montagem do experimento pela produção média de ovosobtida, com a formação das unidades experimentais. A produção dos blocos 1 a 5 foi de $86,0 \pm 1,2 ; 78,8 \pm 1,0 ; 71,0 \pm 0,0 ; 66,2 \pm 0,8$ e $63,6 \pm 0,5 \%$, respectivamente. A produção média de ovos por tratamento foi 73,2; 73,0; 73,2; 73,2 e 73,0\%, com média geral de 73,12\%. No momento da distribuição das aves, realizou-se a pesagem por parcela para cálculo do peso médio inicial.

Os tratamentos consistiram de uma ração basal (Tabela 1), formulada para atender os requerimentos nutricionais das aves, segundo Silva \& Ribeiro (2001), exceto em lisina, e suplementada com 0,$000 ; 0,104 ; 0,207 ; 0,311$ ou $0,414 \%$ de L-lisina.HCL em substituição ao amido de milho para apresentar 0,$88 ; 0,96 ; 1,04 ; 1,12$ ou $1,20 \%$ de lisina digestível.

As codornas foram alojadas em gaiolas galvanizadas com dimensões de $33 \times 33 \times 14$ cm e receberam água e ração à vontade. $\mathrm{O}$ programa de luz adotado foi o de luz contínua durante 24 horas por dia (natural + artificial).

Ao final de cada período, avaliaram-se o consumo de ração (CR , g/ave/dia), a produção de ovos (PR, \%), o peso (PO, g) e a massa (MO, g/ave/dia) de ovos, a conversão alimentar por massa (CMO, g/ave/dia) e por dúzia (CDZ, kg/ duzia) de ovos, os pesos de albúmen (PA, g), gema (PG, g) e casca (PC, g), as porcentagens de albúmen (\%A), gema $(\% \mathrm{G})$ e casca (\%C) e a gravidade específica (GE) dos ovos.

Ao final de cada período experimental, foram coletadas as sobras das rações de cada parcela para cálculo do consumo de ração. A coleta dos ovos foi realizada duas vezes ao dia (às 9 e às 15 h), registrando-se em ficha a freqüência de postura, o número de ovos intactos e defeituosos e a taxa de mortalidade. A produção dos ovos em porcentagem foi calculada dividindo-se a quantidade total de ovos por parcela pelo número de aves. Os ovos dos últimos três dias de cada período experimental foram pesados individualmente para obtenção do peso médio. O cálculo da massa de ovo foi realizado pelo produto da produção de ovos e do peso médio dos ovos por parcela. A conversão alimentar por massa de ovo foi calculada pela relação entre consumo de ração e massa de ovo produzida. A conversão por dúzia de ovos foi calculada como a relação entre o 
Tabela 1 - Composição percentual da ração basal

\begin{tabular}{|c|c|}
\hline Ingrediente & Dieta basal \\
\hline Milho & 59,419 \\
\hline Farelo de soja & 29,240 \\
\hline Calcário & 5,368 \\
\hline Glúten de milho & 2,179 \\
\hline Fosfato bicálcico & 1,316 \\
\hline Óleo de soja & 1,252 \\
\hline Amido & 0,444 \\
\hline Sal & 0,282 \\
\hline DL-metionina & 0,156 \\
\hline Premix mineral $^{1}$ & 0,100 \\
\hline Colina $60 \%$ & 0,100 \\
\hline Treonina & 0,084 \\
\hline Premix vitamínico ${ }^{2}$ & 0,050 \\
\hline Antioxidante $^{3}$ & 0,010 \\
\hline Total & 100,00 \\
\hline \multicolumn{2}{|l|}{ Composição calculada } \\
\hline Energia metabolizável (kcal/kg) & 2.830 \\
\hline Proteína bruta (\%) & 19,9 \\
\hline Cálcio (\%) & 2,50 \\
\hline Fósforo disponível (\%) & 0,35 \\
\hline Cloro (\%) & 0,20 \\
\hline Sódio (\%) & 0,15 \\
\hline Potássio (\%) & 0,72 \\
\hline Lisina digestível (\%) & 0,88 \\
\hline Metionina+cistina digestível (\%) & 0,72 \\
\hline Treonina digestível (\%) & 0,74 \\
\hline Triptofano digestível (\%) & 0,21 \\
\hline \multicolumn{2}{|c|}{ 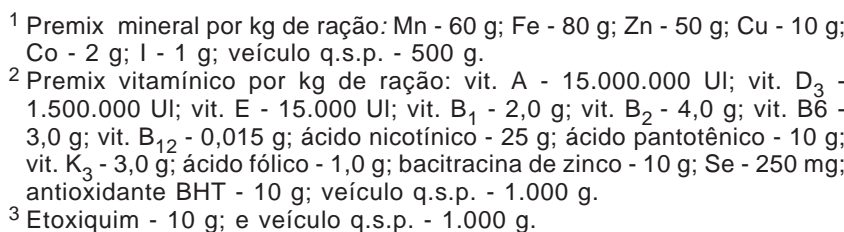 } \\
\hline
\end{tabular}

consumo de ração e a produção; e o resultado multiplicado por 12.

Do total de ovos produzidos por repetição, foram selecionadas seis unidades para determinação dos pesos e das porcentagens de gema, albúmen e casca. Após a separação manual desses componentes, as cascas foram mantidas em estufa a $105^{\circ} \mathrm{C}$ por 4 horas. As porcentagens de gema, albúmen e casca foram obtidas dividindo-se o peso de cada um destes componentes pelo peso do ovo; multiplicando-se o resultado por 100 .

A gravidade específica foi determinada pelo método de flutuação salina, conforme metodologia descrita por Hamiltom (1982). Ao final de cada período experimental, foram selecionadas amostras representativas de dois ovos por parcela e, em seguida, foram feitas imersões dos ovos em diversas soluções salinas com os devidos ajustes para o volume de 25 litros de água com densidades que variavam de 1,060 a 1,100 com intervalo de 0,025 . Os ovos foram colocados nos baldes com as soluções, da menor para a maior densidade, e retirados ao flutuarem registrando-se os valores das densidades correspondentes às soluções dos recipientes. Antes de cada avaliação, as densidades foram conferidas com densímetro de petróleo.

Os dados foram analisados utilizando-se o programa Sistema para Análises Estatísticas e Genética (SAEG), desenvolvido pela Universidade Federal de Viçosa (1999). Foi feita análise de regressão utilizando-se efeitos lineares e quadráticos para determinação da exigência de lisina digestível.

\section{Resultados e Discussão}

À exceção do consumo de ração e da produção de ovos, as outras características de desempenho (Tabela 2) não diferiram $(\mathrm{P}>0,05)$ entre os níveis de lisina avaliados. O consumo de ração (CR) foi influenciado pelos níveis de lisina na dieta $(\mathrm{P}<0,05)$ e diminuiu linearmente de acordo com a equação $\hat{\mathrm{Y}}=34,703-6,1891 \mathrm{x}\left(\mathrm{r}^{2}=0,60\right)$, de modo que, a cada 0,08\% de lisina digestível, a redução foi de 0,5 g de ração.

Resultados diferentes foram obtidos por Oliveira et al. (1999) e Ribeiro et al. (2003), que não verificaram efeito significativo dos níveis de lisina da dieta no consumo de ração. Por outro lado, os resultados obtidos neste estudo foram contrários aos observados por Pinto et al. (2003) de que o aumento dos níveis de lisina da dieta promoveu aumento do consumo. Contudo, quando o consumo diário de lisina digestível foi avaliado por meio da multiplicação dos valores de consumo de ração pelos teores de lisina digestível das dietas, tanto no trabalho de Pinto et al. (2003) quanto neste estudo, houve aumento linear de 25,8 e 21,7 mg, respectivamente, a cada $0,1 \%$ de aumento de lisina digestível. Na pesquisa realizada por Pinto et al. (2003), o consumo de lisina digestível variou de 177 a $304 \mathrm{mg}$, enquanto neste estudo a variação foi de 253 a $320 \mathrm{mg}$. Semelhante ao que ocorre com o nível energético da dieta, possivelmente o nível de lisina da dieta é outro fator de regulação do consumo diário de ração por codornas japonesas em postura (Barreto et al., 2007). De acordo com Goulart (1997), o excesso de aminoácidos circulante no sangue pode provocar diminuição do consumo de ração pelos animais.

A produção de ovos (PR) foi influenciada de forma quadrática pelos níveis de lisina digestível da dieta e foi maior (93,3\%) no nível de 1,03\% de lisina digestível, de acordo com a equação $\hat{\mathrm{Y}}=-111,74+398,03 \mathrm{x}-193,16 \mathrm{x}^{2}$ $\left(r^{2}=0,96\right)$ (Figura 1$)$. Considerando esse valor e a equação de consumo de ração, estimou-se a exigência diária de 292 mg de lisina digestível para melhor produção de ovos em codornas japonesas em postura. 
Tabela 2 - Consumo de ração (CR), produção (PR), peso do ovo (PO), massa de ovos (MO) e conversão por massa (CMO) e por dúzia de ovos (CDZ) em codornas alimentadas com rações com diversos níveis de lisina digestível

\begin{tabular}{|c|c|c|c|c|c|c|}
\hline Lisina digestível (\%) & CR (g/ave/dia) & PR (\%) & PO (g) & MO (g/ave/dia) & CMO (kg/kg) & $\mathrm{CDZ}(\mathrm{kg} / \mathrm{dz})$ \\
\hline 0,880 & 28,8 & 89,2 & 12,5 & 10,6 & 2,597 & 0,388 \\
\hline 0,960 & 29,2 & 91,7 & 12,4 & 11,1 & 2,589 & 0,383 \\
\hline 1,040 & 27,9 & 93,9 & 12,3 & 11,4 & 2,413 & 0,357 \\
\hline 1,120 & 28,6 & 91,7 & 12,2 & 10,5 & 2,559 & 0,375 \\
\hline 1,200 & 26,7 & 87,7 & 12,5 & 10,2 & 2,441 & 0,365 \\
\hline Média & 28,3 & 90,8 & 12,4 & 10,7 & 2,520 & 0,374 \\
\hline Exigência & - & 1,030 & - & - & - & - \\
\hline Regressão & $\mathrm{L}^{*}$ & $\mathrm{Q} * *$ & ns & ns & ns & ns \\
\hline CV (\%) & 4,80 & 2,77 & 2,71 & 4,39 & 6,13 & 5,22 \\
\hline
\end{tabular}

$\mathrm{CV}=$ coeficiente de variação.; ns = não-significativo; $L=$ efeito linear; $Q=$ efeito quadrático; ${ }^{*}=5 \%$ de probabilidade; ${ }^{\star}=1 \%$ de probabilidade.

Tabela 3 - Peso de albúmen (PA), gema (PG) e casca (PC), porcentagem de albúmen (\%A), gema (\%G) e casca (\%C) e gravidade específica (GE) dos ovos de codornas japonesas alimentadas com rações contendo diversos níveis de lisina digestível

\begin{tabular}{|c|c|c|c|c|c|c|c|}
\hline Lisina digestível (\%) & PA (g) & PG (g) & PC (g) & $\%$ A (\%) & \%G (\%) & \%С (\%) & GE $(\%)$ \\
\hline 0,88 & 6,89 & 4,25 & 1,07 & 55,3 & 34,1 & 8,6 & 1,069 \\
\hline 0,96 & 6,94 & 3,99 & 1,08 & 56,3 & 32,4 & 8,7 & 1,070 \\
\hline 1,04 & 7,09 & 3,92 & 1,06 & 57,5 & 31,8 & 8,6 & 1,070 \\
\hline 1,20 & 7,31 & 3,89 & 1,04 & 58,7 & 31,2 & 8,4 & 1,070 \\
\hline Exigência & - & - & - & - & - & - & - \\
\hline Regressão & ns & ns & ns & ns & ns & ns & ns \\
\hline
\end{tabular}

$\mathrm{CV}=$ coeficiente de variação; ns = não-significativo.

O consumo de ração observado neste estudo evidencia que, antes do ponto máximo, a dieta estava deficiente em lisina digestível ou com desbalanço de lisina em relação a outros aminoácidos, visto que a adição de lisina resultou em aumento da produção de ovos. A partir do ponto de máximo, o nível de lisina passou a ser excessivo, o que resultou em sua excreção e em desperdício de energia, provocando redução na produção de ovos. Segundo Leclercq (1998), o excesso de aminoácidos é catabolizado e excretado na forma de ácido úrico. Considerando que o custo metabólico para incorporar um aminoácido na cadeia protéica é estimado em $4 \mathrm{~mol}$ de ATP e que o custo para excretar um aminoácido é estimado em torno de 6 a $18 \mathrm{~mol}$ de ATP e pode variar de acordo com a quantidade de nitrogênio do aminoácido (Costa et al., 2001), a eliminação desses aminoácidos tem alto custo energético para as aves. Dessa forma, a utilização de 1,03\% de lisina digestível na dieta resultaria em maior quantidade de energia para as aves, que seria utilizada para produção de ovos.

Resultados semelhantes foram observados por Ribeiro et al. (2003), que verificaram maior produção de ovos com 1,07 e 1,15\% de lisina total em rações contendo 20 ou 23\% PB, respectivamente. Do mesmo modo, Pinto et al. (2003) estimaram para melhor produção de ovos exigência de 1,045\% de lisina digestível na dieta.

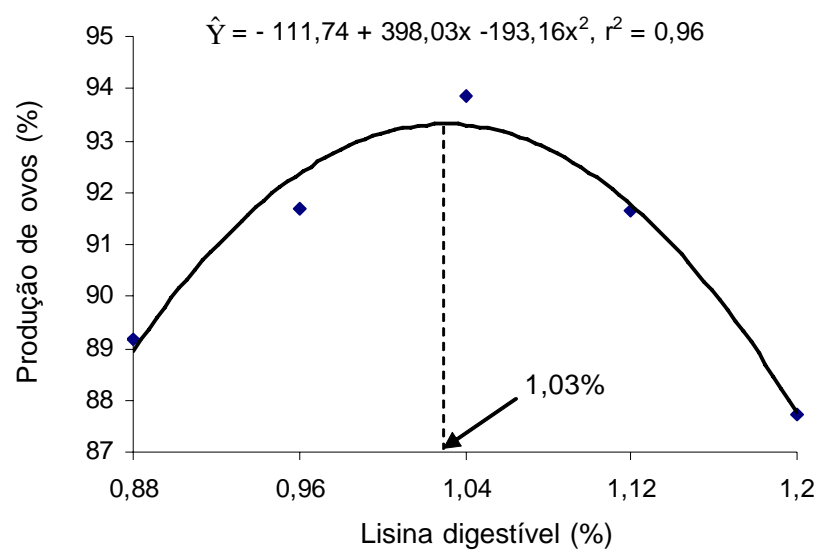

Figura 1 - Produção de ovos de codornas japonesas alimentadas com rações com diversos níveis de lisina digestível.

As características de qualidade dos ovos não foram influenciadas $(\mathrm{P}>0,05)$ pelos níveis de lisina digestível nas dietas (Tabela 3). Resultados semelhantes foram encontrados por Oliveira et al. (1999) e Ribeiro et al. (2003).

Pinto et al. (2003), avaliando as exigências de lisina digestível para codornas em início de postura, verificaram redução linear da porcentagem de casca dos ovos com o aumento do nível de lisina nas dietas. Segundo esses autores, essa redução foi ocasionada pelo aumento na produção e no peso dos ovos com o aumento dos níveis de lisina. 


\section{Conclusões}

A exigência de lisina digestível estimada para codornas japonesas em postura é de 1,030\% da ração, que corresponde a um consumo diário de $292 \mathrm{mg}$.

\section{Agradecimento}

À Granja Fujikura, do estado de São Paulo.

\section{Literatura Citada}

BARRETO, S.L.T.; ARAUJO, M.S.; UMIGI, R.T. et al. Exigência nutricional de lisina para codornas européias machos de 21 a 49 dias de idade. Revista Brasileira de Zootecnia, v.35, n.3, p.750-753, 2006.

COSTA, F.G.P.; ROSTAGNO, H.S.; ALBINO, L.F.T. et al. Níveis dietéticos de proteína bruta para frangos de corte de 1 a 21 e 22 a 42 dias de idade. Revista Brasileira de Zootecnia, v.30, n.5, p.1498-1505, 2001.

GOULART, C.C. Exigência nutricional de lisina para poedeiras leves e semipesadas. Viçosa, MG: Universidade Federal de Viçosa, 1997. 51p. Dissertação (Mestrado em Zootecnia) Universidade Federal de Viçosa, 1997.

HAMILTOM, R.M.G. Methods and factors that affect the measurement off egg shell quality. Poultry Science, v.61, p.2002-2039, 1982.

LEANDRO, N.S.M.; VIEIRA, N.S.; MATOS, M.S. et al. Desempenho produtivo de codornas japonesas (Coturnix coturnix japonica) submetidas a diferentes densidades e tipos de debicagem. Acta Scientiarum. Animal Sciences, v.27, n.1, p.129-135, 2005.
LECLERCQ, B. Specific effects of lysine on broiler production: comparison with threonine and valine. Poultry Science, v.77, p.118-123, 1998.

NATIONAL RESEARCH COUNCIL - NRC. Nutrient requirements of poultry. 9.ed. Washington, D.C.: National Academy Press, 1994. 155p.

OLIVEIRA, A.M.; FURLAN, A.C.; MURAKAMI, A.E. et al. Exigência nutricional de lisina para codornas japonesas (Coturnix coturnix japonica) em postura. Revista Brasileira de Zootecnia, v.28, n.5, p.1050-1053, 1999.

PINTO, R.; FERREIRA, A.S.; DONZELE, J.L. et al. Exigência de lisina para codornas japonesas em postura. Revista Brasileira de Zootecnia, v.32, n.5, p.1182-1189, 2003.

RIBEIRO, M.L.G.; SILVA, J.H.V.; DANTAS, M.O. et al. Exigências nutricionais de lisina para codornas durante a fase de postura, em função do nível de proteína da ração. Revista Brasileira de Zootecnia, v.32, n.1, p.156-161, 2003.

SILVA, J.H.V.; RIBEIRO, L.G.R. Tabela nacional de exigência nutricional de codornas japonesas (Coturnix coturnix japonica). Bananeiras: DAP/UFPB/Campus IV, 2001. 19p.

SILVA, M.A.; CORRÊA, G.S.S.; CORRÊA, A.B. et al. Influência da proteína bruta eenergia metabolizável da dieta sobre a composição de carcaça de codornas européias. In: REUNIÃO ANUAL DA SOCIEDADE BRASILEIRA DEZOOTECNIA, 42. 2005, Goiânia. Anais... Goiânia: Sociedade Brasileira de Zootecnia/Gmosis, [2005]. (CD-ROM).

TON, A.P.S. Exigências de lisina digestível e energia metabolizável de codornas de corte (Coturnix coturnix sp) em crescimento, com base no conceito de proteína ideal. Maringá: Universidade Estadual de Maringá, 2007. 56p. Dissertação (Mestrado em Zootecnia) - Universidade Estadual de Maringá, 2007.

UNIVERSIDADE FEDERAL DE VIÇOSA - UFV. Manual de utilização do programa SAEG - Sistema de análise estatística e genética. Viçosa, MG: Universidade Federal de Viçosa, 1999. $59 p$. 